\title{
Donald Trump e o Neoconservadorismo
}

\section{Donald Trump and Neoconservantism}

\author{
Carlos Gustavo Poggio Teixeira ${ }^{1}$ \\ José Felipe Ribeiro Calandrelli ${ }^{2}$
}

Resumo: A relação dos neoconservadores com o Partido Republicano nasceu quando os mesmos resolveram apoiar a candidatura de Ronald Reagan. Desde então, o grupo tem sido identificado como parte do espectro Republicano norte-americano. Nas eleições de 2016, alguns expoentes do pensamento neoconservador se opuseram à eleição de Donald Trump chegando inclusive a apoiar a candidata Democrata, Hillary Clinton. A partir o exame da literatura produzida pelos próprios neoconservadores em relação a Trump e também da literatura sobre neoconservadorismo, buscou-se compreender o apoio à Clinton sob a luz do pensamento "neocon" e compreender o que isto significa para os mesmos. Analisando-se os pontos centrais da ideologia que guiam suas ações e discursos, além da literatura produzida recentemente acerca do tema estudado, conclui-se que o apoio à candidata Democrata é muito mais condizente com essa corrente de pensamento, mas que isso não deve representar uma debandada de neoconservadores do Partido Republicano.

Palavras-chave: neoconservadorismo; Donald Trump; eleições presidenciais americanas de 2016; Estados Unidos

\begin{abstract}
The relation of neoconservatives with the Republican Party emerged when they decided to support the candidacy of Ronald Reagan. Since then, the group is being identified as part of the north-American republican spectrum. In 2016 elections some exponents of the neoconservative thinking were opposed to the election of Donald Trump even supporting the democrat candidate Hillary Clinton. By examining the literature produced by the conservatives themselves in relation to Trump and also the literature regarding neoconservativism, we

(c) EY Direito autoral e licença de uso: Este artigo está licenciado sob uma Licença Creative Commons. Com essa licença você pode compartilhar, adaptar, para qualquer fim, desde que atribua a autoria da obra, forneça um link para a licença, e indicar se foram feitas alterações.
\end{abstract}


tried to understand the support for Clinton in the light of "neocon" thought and what it means. Analyzing the main issues of the ideology that guide their actions and discourses, added to the current literature produced about the studied theme, it is possible to reason that the support for the democratic candidate is much more consistent with this line of thought. However, this should not represent a fleeing of neoconservatives from the Republican party.

Keywords: neoconservantism; Donald Trump; 2016 US presidential elections; United States

\section{Introdução}

De acordo com muitos analistas, a eleição de Donald Trump estaria relacionada com a ascensão do conservadorismo nos Estados Unidos. Entretanto, se considerarmos as principais vertentes do conservadorismo americano, o quadro torna-se um pouco mais complexo. Quando levamos em consideração as três principais vertentes do pensamento conservador nos Estados Unidos, quais sejam, o conservadorismo social, o libertarianismo e o neoconservadorismo, verificamos que o presidente americano não pode ser encaixado em nenhuma delas. No caso dos primeiros, o histórico de divórcios, escândalos sexuais, apoio ao casamento gay e posição ambígua no caso do aborto, tornam Trump um candidato pouco atrativo. Para os chamados libertários, a postura protecionista de Trump é mais próxima do socialista Bernie Sanders do que da tradicional atitude favorável ao livre comércio que prevalece no Partido Republicano. Entretanto, os críticos mais ferrenhos do atual presidente dentro do campo conservador, tanto durante a campanha como depois da eleição, tem vindo por parte dos neoconservadores.

Desde 2016, os neoconservadores têm se concentrado em atacar fortemente Donald Trump. Investidas questionando a veracidade dos discursos do presidente, seu relacionamento com Putin e uma alegada influência russa nas eleições americanas, além da investigação do FBI, são frentes de ataque comum dos chamados "neocons" contra Trump. Muitos neoconservadores, refutando veementemente a postura isolacionista pregada pelo então candidato Republicano, mostraram-se a favor de Hillary Clinton durante as eleições de 2016. Algumas questões surgem a partir do apoio à Democrata em detrimento do Republicano. Este artigo propõe descrever a relação dos neocons com Trump e demonstrar que o ponto-chave do pensamento neoconservador que os aproximou da candidata republicana é o intervencionismo defendido por essa corrente de pensamento que se assemelha à posição liberal hawk de Hillary Clinton. Não obstante, é fundamental compreender as bases que fundamentam o neoconservadorismo para que se entenda a postura dos mesmos contra Trump. 
Para tal, esse artigo será dividido em três partes. A primeira seção explica os pontos centrais do pensamento neoconservador A segunda parte explorará a postura dos neoconservadores durante as eleições presidenciais de 2016 e após a vitória do atual presidente norte-americano, tendo como marcos importantes o bombardeio à Síria em 6 de abril de 2017 e o balanço por conta dos 100 dias de governo Trump. Nessa parte, será feito um apanhado de artigos produzidos por autores como Robert Kagan, William Kristol, Charles Krauthammer, Richard Lowry e Max Boot. Esses autores foram escolhidos por representarem aqueles que se reconhecem deliberadamente neoconservadores e que estão mais ativos atualmente na mídia americana. Eles não só apoiaram como influenciaram a chamada "Doutrina Bush" e a invasão do Iraque em 2001, ação do governo americano que foi criticada por Trump ainda durante sua campanha presidencial. Na parte final do artigo, uma breve conclusão buscará avaliar a possibilidade de os neoconservadores abandonarem o Partido Republicano em um futuro próximo.

\section{Das Origens do Neoconservadorismo ao 11 de Setembro}

A origem do neoconservadorismo pode ser traçada a um grupo de antigos Trotskistas que, ao longo dos anos 1940 e 1950, tornaram-se liberais defensores do Estado de bem-estar social e do New Deal, e, portanto, mais próximos do Partido Democrata. Contudo, com o surgimento da contracultura nos anos 1960 houve uma ruptura dentro dos chamados liberais do centro vital. Uns se incorporam de vez com a Nova Esquerda e outros, afastaram-se desta nova vertente. Os liberais que se distanciaram foram chamados de "neoconservadores". Porém, eles não pertenciam e não compartilhavam de crenças conservadoras amplamente representadas à época por periódicos como o National Review. Não se tratavam, portanto, de conservadores tradicionais como entendido nos anos 1960. Dentre os pontos compartilhados por esse grupo estavam: descrédito nas instituições, crise moral e ideológica - crítica ao comunismo e a nova esquerda - e a defesa da democracia como um valor supremo.

Durante duas décadas os neoconservadores, por serem dissidentes liberais, mantiveram-se próximos do Partido Democrata. Entretanto, em 1972, a nomeação de George McGovern como candidato do Partido Democrata fez com que muitos autodenominados neoconservadores apoiassem o Republicano Richard Nixon nas eleições daquele ano. Sob alegações de que o Partido Democrata estaria se aproximando demasiadamente da nova esquerda, a nomeação de McGovern, cujo slogan de campanha era "Come Home America", foi um fator decisivo para a fuga dos neoconservadores. O candidato tinha uma postura considerada excessivamente pacifista, sendo que para os neoconservadores isso era interpretado como uma fraqueza na luta contra o comunismo em um momento crucial do envolvimento dos Estados Unidos na Guerra do Vietnã. 
Destaca-se a importância dada pelos neoconservadores à política externa dos Estados Unidos. Influenciados pelo medo da expansão do comunismo o pensamento neoconservador passou a concentrar-se em questões como defesa da democracia, promoção de direitos humanos e a preocupação com a assertividade e a supremacia do poder militar americano. Esses pontos foram fundamentais para o apoio à eleição do Republicano Ronald Reagan em 1980. Reagan, que defendia a supremacia americana e acreditava na responsabilidade dos Estados Unidos em defender valores democráticos como um contraponto à URSS, aceitou de bom grado esse apoio como aliados no combate ideológico da Guerra Fria. Reagan viu o governo soviético ruir durante seu segundo mandato. Os neoconservadores reivindicavam o crédito junto ao presidente por terem derrotado o regime comunista.

Durante os anos 1990, com a ameaça comunista fora do radar, acreditouse que os neoconservadores perderiam relevância. Apesar do discurso de expansão de regimes e valores democráticos, dizia-se que a principal motivação para a existência do neoconservadorismo - a luta contra o comunismo - havia desparecido. John Podhoretz, um dos neoconservadores mais importantes, chegou a escrever o "obituário" do neoconservadorismo. ${ }^{3}$ Contudo, com os ataques terroristas de setembro de 2001, os neoconservadores ganharam um novo inimigo para substituir o comunismo como elemento organizador dessa linha de pensamento: o terrorismo, particularmente o proveniente de grupos islâmicos ${ }^{4}$. Dentro da administração Bush, elementos identificados ou influenciados por ideias neoconservadoras passaram a ganhar espaço, resultando na invasão do Iraque em março de 2003.

\section{Elementos Essenciais do Pensamento Neoconservador}

O pensamento neoconservador possui quatro temas principais em termos de política externa. São eles: internacionalismo não-institucional, unilateralismo, democracia e poder militar ${ }^{5}$. Esses quatro elementos formam um conjunto de princípios básicos que servem como núcleo dos argumentos neoconservadores e que os distinguem como tais. Destaca-se que os temas se interconectam e são consequências um do outro. "Assim, uma postura de política externa com base em fatores morais pode levar a um unilateralismo, que, por sua vez, necessariamente dispensaria o apoio de instituições internacionais e que, para sobreviver, necessitaria de um intenso suporte militar". ${ }^{6}$

No que se refere à ideia de internacionalismo não-institucional, "do ponto de vista dos neoconservadores, os Estados Unidos deveriam assumir definitivamente o papel de 'superpotência', o que consequentemente significaria maior envolvimento nos conflitos internacionais". ${ }^{7}$ Portanto,

uma das principais características do pensamento neoconservador em política externa é justamente seu caráter 
eminentemente internacionalista, marcado pela defesa de um envolvimento ativo nos assuntos globais, a partir da crença de que os Estados Unidos têm a responsabilidade, a capacidade e o interesse na construção de uma ordem internacional que satisfaça seus objetivos. ${ }^{8}$

Assim, os neoconservadores defendem que os Estados Unidos deveriam protagonizar uma "Hegemonia Benevolente", que, como explica Stephens ${ }^{9}$, é o mesmo que dizer que os Estados Unidos deveriam ser a "Polícia do Mundo" a fim de garantir uma ordem no sistema internacional que poderia ser denominada como uma "Pax Americana". Vaïsse reforça que os neoconservadores acreditam que "Os Estados Unidos têm uma responsabilidade especial, uma vocação especial [...] devem desempenhar um papel ativo no mundo a fim de defender e proporcionar uma ordem internacional pacífica liderada pelo país". ${ }^{10}$

O neoconservadorismo compreende que para a finalidade de garantir uma ordem mundial moldada pelos Estados Unidos é necessário que o país mantenha uma postura unilateral frente aos desafios de se lidar com a comunidade internacional. Define-se essa posição como

um unilateralismo com interesses globais, visando à manutenção e à preservação da ordem internacional estabelecida mediante apoio ativo à democracia por parte dos Estados Unidos. Ao falar em unilateralismo [...] entende que o unilateralismo não significa "'retirar-se de toda e qualquer aliança", mas livrar os Estados Unidos de alianças que, no seu entendimento, impediriam uma ação mais livre por parte desse país. [...] Agir unilateralmente não significa necessariamente agir sozinho, mas não "permitir tornar-se refém de outros". ${ }^{11}$

As defesas do pensamento neoconservador para inferir o porquê da posição unilateralista fundamentam-se em dois principais argumentos. " $\mathrm{O}$ primeiro, $[\ldots]$ refere-se a uma alegada falta de legitimidade de organismos supranacionais. O segundo argumento fundamenta-se na premissa de que o unilateralismo é necessário para aumentar o raio de ação da superpotência no plano internacional". ${ }^{12}$ Para os neoconservadores, "a ONU não é apenas não efetiva, como é ilegítima”. Dessa forma, "a legitimidade de ação advém somente do povo norte-americano e da responsabilidade que os Estados Unidos têm de manter a ordem". ${ }^{13}$ Entende-se, portanto, duas importantes características do pensamento neoconservador, a certeza de que os Estados Unidos devem conduzir o sistema internacional para se manter a ordem e a descrença em outros poderes que poderiam limitar sua ação - não apenas instituições internacionais, mas também outros países. 
O terceiro ponto destacado como tema fundamental para o pensamento neoconservador é a questão da democracia. Os neoconservadores, ao enfatizarem a relação intrínseca entre a promoção da democracia e o interesse nacional norte-americano, e "“ao entenderem que essa estratégia [de promoção da democracia] é essencial para garantir a segurança dos Estados Unidos e reforçar sua supremacia no cenário internacional", defendem que a democracia é tanto um imperativo de segurança quanto um imperativo moral. ${ }^{14}$

A relação entre democracia e segurança, cuja presença no discurso neoconservador é central relaciona-se com a crença liberal sintetizada na chamada Teoria da Paz Democrática. Ela se baseia em duas crenças principais: "a primeira é de que democracias não lutam entre si. A segunda é de que, quando as democracias entram em conflito, apenas raramente recorrem ao uso da força, pois isto seria considerado ilegítimo". A teoria vem da hipótese de que "as normas e culturas democráticas [...] impediriam os estados democráticos de irem à guerra com outras democracias [...] e baseiam-se na premissa de que, do ponto de vista das democracias, seria injusto ou imprudente entrar em guerra com outras democracias". ${ }^{15}$ Para os neoconservadores, a única forma de se criar um ambiente favorável para os Estados Unidos seria encorajando a proliferação de regimes democráticos, já que pesquisas confirmaram a intuição de que quanto mais democrático o mundo for, mais pacífico ele será.

Por conseguinte, os neoconservadores defendem que os Estados Unidos, junto com seus aliados, devem impedir que Estados não-democráticos, considerados hostis, dominem regiões centrais aos interesses norte-americanos. Acreditam que o governo americano deve trabalhar a fim de construir um ambiente internacional mais condizente com seus valores: "uma pacífica ordem democrática na qual as nações são capazes de perseguir seus interesses legítimos sem se preocupar com nenhuma dominação mundial". ${ }^{16}$

A partir do entendimento da necessidade de intervenção defendida pelos neoconservadores, pode-se compreender o quarto ponto fundamental do pensamento, que é o foco no poder militar. Enquanto o pensamento liberal acredita que leis e instituições devem garantir a ordem e que o uso da força deve ser apenas considerado em última instância, os neoconservadores acreditam que a força se encontra acima das leis e instituições. Ao negligenciarem a eficácia do multilateralismo e defenderem o unilateralismo norte-americano, eles confiam no "poder" que o uso da força proporciona acima do "papel" desempenhado pelas instituições internacionais. Ou seja, para perpetuar a supremacia de poder norte-americano, "os neoconservadores advogam por uma política externa altamente militarizada que clama por demonstrações vigorosas do poder". ${ }^{17}$ Portanto

embora a ação coletiva seja boa, a América deveria ser livre para agir unilateralmente: a legitimidade do ato advém somente do povo americano e da única responsabilidade 
que os Estados Unidos têm de manter a ordem. [...] E para manter essa ordem, o país necessita de recursos militares massivos assim como a vontade política de os usar. Isso significa que a nação deve sustentar o gasto militar pela possibilidade de agir/intervir rapidamente e fortemente em qualquer região do mundo. ${ }^{18}$

Em suma, os neoconservadores acreditam fortemente na proeminência dos Estados Unidos frente a quaisquer outras formas de poder no mundo tanto outros países, quanto instituições internacionais ou outros modelos de multilateralismo. Consequentemente, afirmar o dever americano de regular e proteger o mundo ativamente através da promoção da democracia faz com que os mesmos reafirmem a necessidade de um forte e grande aparato militar.

\section{Os Neoconservadores e o Candidato Donald Trump}

Frente aos sucessivos ataques dos neoconservadores ao governo Obama, não é surpresa que esses tenham tomado parte nas eleições presidenciais de 2016. A crítica neoconservadora a Donald Trump remonta ao início de sua campanha. Durante toda a trajetória, alguns pensadores neoconservadores se posicionaram contra as propostas do Republicano, principalmente no que tange aos discursos em matéria de política externa. Conhecidos por sua defesa da ideia dos Estados Unidos como polícia do mundo e sua postura belicista, argumentavam que Trump estaria se voltando a um isolacionismo perigoso que colocaria em risco a ordem internacional liberal. Não obstante, em 2016, um grupo de neoconservadores se uniu a favor da candidatura de Hillary Clinton. Pode-se entender o apoio de parte significativa dos neoconservadores, que desde os anos 70 eram próximos do Partido Republicano, à candidata Democrata como uma sintonia ideológica intervencionista dos dois lados. Hillary Clinton era vista como uma candidata mais próxima das ideias neoconservadoras já que ela concordava com a necessidade dos Estados Unidos agirem de forma enfática no sistema internacional - como se posicionar contra os ímpetos do governo Putin e contra os ditadores Assad e Kim Jong-un.

Nesse sentido, um dos principais expoentes do neoconservadorismo, Robert Kagan, apoiou declaradamente a candidatura da Democrata chegando a participar de um evento denominado Foreign Policy Professionals for Hillary with Robert Kagan, Julianne Smith and Amanda Sloat, ocorrido em 21 de julho de 2016. Esse movimento parece indicar que parte importante dos neoconservadores estariam retornando à órbita do Partido Democrata, desfazendo um movimento de incorporação ao Partido Republicano que havia começado nos anos 70 e se fortalecido com a eleição de Reagan.

A posição política intervencionista conhecida como liberal hawk, associada a visão de mundo de Hillary Clinton, embora seja defensora de uma postura militar agressiva, possui uma postura mais progressista e com maiores 
preocupações com instituições internacionais. O pensamento neoconservador, por exemplo, ao se declarar contra a ONU e um sistema multilateral se distingue do intervencionismo defendido por Clinton e pelos internacionalistas liberais que dá mais ênfase à necessidade da aprovação do sistema internacional para as intervenções americanas.

Mas por que Hillary Clinton? Hudson ${ }^{19}$ destaca que enquanto o governo Obama não adotava uma postura de cunho intervencionista forte durante a Primavera Árabe, Clinton sempre se posicionou a favor de intervenções norteamericanas na região. Colocação que, como observa Khalek, ${ }^{20}$ soma-se aos discursos que evidenciam a crença da candidata de que "o estabelecimento de uma forte política externa norte-americana é justo e que o crescente populismo é ingênuo e desinformado ao apresentar uma hostilidade frente ao intervencionismo". ${ }^{21}$ Além do populismo atacado por Hillary, em um claro ataque a Donald Trump, ainda afirma Khalek, o isolacionismo do candidato republicano levou muitos neoconservadores a retirarem seu apoio à candidatura republicana. ${ }^{22} \mathrm{E}$ alguns, como Kagan, ainda apoiaram ativamente a candidatura de Clinton". ${ }^{23}$

Uma última consideração necessária para compreensão do posicionamento neoconservador quanto às eleições presidenciais é sua posição frente ao movimento Never Trump. O movimento nasceu dentro do partido republicano quando ficou claro que Trump teria chances de ganhar as primárias. Esta aliança se propunha de barrar a eleição do atual presidente dentro do próprio espectro republicano de votos. ${ }^{24}$ William Kristol é um exemplo importante de neoconservador que se juntou ao movimento. Alegando que Trump é uma pessoa "repulsiva", que ele não "serve" para ser presidente e acreditando que o mesmo possa causar "danos irreparáveis" ao país, William Kristol foi um fervoroso "never trumper". ${ }^{25}$

\section{Os Neoconservadores e o Presidente Donald Trump}

Mesmo com os ataques dos neoconservadores a Trump e o apoio de alguns a Hillary Clinton, chegando ao ponto de associar o republicano ao fascismo $^{26}$, os esforços somados não foram suficientes para impedir a eleição do empresário. Já no final de 2016, com a eleição confirmada de Trump, os neoconservadores não mudaram sua posição de crítica e continuaram a disparar contra o atual presidente dos Estados Unidos. Nas vésperas da eleição, Kristol escreve que teve orgulho de participar ativamente contra o candidato republicano durante toda a campanha ${ }^{27}$. A postura crítica vigorou também durante os primeiros meses de 2017, até o bombardeio feito pelo governo americano na Síria. Dentre os críticos mais ferrenhos de Trump, destaca-se o neoconservador Max Boot.

Próximo dos 100 primeiros dias do republicano em exercício do poder, Boot elencou em um artigo as principais razões do governo Trump ser um 
absurdo sem precedentes. Destacou primeiro o envolvimento determinante da Rússia para eleição do presidente, além de questionar a admiração de Trump pelo "ditador russo" Putin. Realçou o fato do presidente estar sendo investigado pelo FBI e, ao mesmo tempo, ainda atacar Obama acusando-o de ter grampeado seus telefones. Soma-se à investigação do FBI a acusação constante de que o republicano mente. O neoconservador ressalta pesquisa do PolitiFact que mostra que apenas 17\% das declarações de Trump são verdadeiras. Quanto à performance do presidente dentro da Casa Branca, Boot criticou todas as escolhas feitas para compor o staff do governo, além das polêmicas com o judiciário - Trump ataca o juiz federal que questionou sua ordem executiva quanto a política de imigração americana - e com a mídia - chamando a mídia americana de "inimiga". Criticou também medidas centrais da administração do Republicano como sua política de imigração e a reforma do Obamacare.

A desaprovação do neoconservador não se limita apenas ao cenário interno americano e aos aspectos pessoais do presidente. Boot salienta especialmente as controvérsias da política externa apresentada até o momento da escrita do artigo. Enfatiza os conflitos de interesse privados de Trump com os da administração federal. Crítica a postura do presidente com a China, questiona como o republicano conseguiu ofender tantos aliados em tão pouco tempo - se referindo a Alemanha, Austrália, Suécia, França e Reino Unido, e por fim ataca a falta de conhecimento político de Trump - como sua ignorância frente ao Acordo de Parceria Transatlântica de Comércio e Investimento, mais conhecido como TTIP. Por fim, termina afirmando que, frente a todos esses pontos destacados, é mais do que compreensível esse ser o gabinete com maior desaprovação nos primeiros dias de governo da história dos Estados Unidos. ${ }^{28}$

\section{O Bombardeio à Síria: Um Momento de Respiro}

Poucos dias após o artigo fortemente crítico de Boot, o presidente ataca a Síria no dia 6 de abril. Sustentados por Krauthammer, Kagan e Boot, o discurso neoconservador aprovou o ataque, figurando como o primeiro momento de apoio a Trump desde a campanha presidencial.

Krauthammer, que nunca apoiou Hillary Clinton, mas que também afirmou que jamais votaria em Donald Trump ${ }^{29}$, um dia após o ataque, concedeu uma entrevista para a Fox News em que concorda plenamente com o lançamento dos mísseis e ainda diz que considera "extremamente importante" a mensagem enviada para Assad e seus aliados, Rússia e Irã, de que o governo americano não será relutante em mostrar força. Em um claro ataque a relutância de Obama em agir no cenário internacional, defende que "um novo xerife", em referência a ideia de os Estados Unidos serem a polícia do mundo, chegou no cenário internacional. ${ }^{30}$

Em outro artigo, Krauthammer retomou as críticas prévias ao governo Trump afirmando que, como todos, foi surpreendido com a mudança na política 
externa com o bombardeio à Síria, principalmente quando essa atitude partiu de um presidente que desde sua candidatura renunciava o consenso americano de que os Estados Unidos deveriam pagar os custos da liderança mundial. Contudo, reconheceu que Trump agiu. Independente de não ter sido um ato guiado por uma ideia de expansão e garantia da democracia, ponto central do pensamento neoconservador, Krauthammer defendeu a ação e afirmou que no final a lição é de que, apesar dos discursos pessoais do presidente, o interesse nacional prevaleceu. Por fim, admitiu que, apesar do ataque, Trump poderia mudar de ideia a qualquer momento e, mais uma vez, ignorar a necessidade de ação americana no cenário internacional. ${ }^{31}$ Com esse argumento final, evidencia-se uma postura de cautela do autor que é compartilhada pelos demais neoconservadores.

Para a National Review, Richard Lowry ponderou que os adeptos do presidente não deveriam superar tão rápido o acontecido e que também seus críticos de postura intervencionista mais ferrenhos não deveriam se empolgar tanto com as atitudes tomadas pelo governo nos dias que seguiram o ataque. Lowry referiu-se aos ataques aéreos na Síria, à bomba explodida em território afegão e ao envio de um porta-aviões rumo a Coreia do Norte. Para o autor, com sua visão política rudimentar, Trump tem mais uma atitude do que propriamente uma doutrina definida. Lowry chama a atenção para a mudança de discurso do Republicano - durante um evento patrocinado pela própria revista, o presidente declarou que "o mundo é mais pacífico e mais próspero quando os Estados Unidos são mais fortes [...] e a América continuará a fazer o papel de mantenedor da paz"', e afirmou que Trump reconheceu que não existe a possibilidade de ser um presidente americano isolacionista em pleno século XXI. Porém, o autor alertou que, embora haja mudança significativa do discurso em comparação à sua campanha, as ações tomadas pela Casa Branca podem ter sido apenas uma mensagem para reafirmar a presença americana no mundo. Como sublinha Lowry, "todos os neoconservadores são intervencionistas, mas nem todos intervencionistas são neoconservadores". Lowry justifica citando que em nenhum momento Trump relacionou os ataques à defesa e expansão dos valores democráticos - ponto central do pensamento neoconservador. ${ }^{32}$

Já Max Boot precisou de apenas um dia para questionar as verdadeiras intenções do presidente. Em artigo escrito para a revista Commentary, o neoconservador louva o ataque, mas demandava que Trump explicasse para a nação quais os motivos que o levaram a adotar uma ação tão contrária a seus discursos prévios e também que ele esclarecesse o que esse movimento significaria para o futuro da política externa americana. Boot levantou ainda a ideia de que a explicação seria de que o presidente teria apenas respondido às emoções que sentiu ao ver crianças sírias sendo mortas em reportagem da Fox News. 
Por fim, Boot argumentou que, ao contrário da relutância e Obama, o perigo com Trump seria a sua impetuosidade descontrolada sem um ordenamento ideológico de sua política externa. ${ }^{33}$. Em artigo escrito para a Foreign Policy, Boot caracterizou o Trump apresentado com os mísseis na Síria, a bomba no Afeganistão e o porta-aviões na Coreia do Norte como uma "versão 2.0" do presidente. Admite certo otimismo, acreditando que talvez o líder americano esteja sendo influenciado pelo establishment mas, se mostra confuso com essa mudança, questionando se o presidente não poderia mudar de ideia. Para Boot, a imprevisibilidade do homem mais poderoso do mundo é um sério risco a estabilidade do sistema internacional liberal gerando falta de confiança não só para o povo americano, mas também assustando os aliados. ${ }^{34}$

Robert Kagan também comentou o acontecido na Síria. Como os demais neoconservadores, aprovou o ataque, mas também se colocou cauteloso. De forma coerente com o pensamento neoconservador, o autor cobra do presidente americano que aprofunde sua intervenção no país. Defendeu que os mísseis seriam apenas o primeiro passo de uma campanha maior para se acabar com as atrocidades do governo Assad e ainda recuperar a predominância do poder americano na região do Oriente Médio. Terminou declarando que com essa ação teria começado o teste da capacidade de resolução de Trump e previu que se o presidente não tiver a coragem de continuar com a investida, seria pior para o país - passaria a ideia de que o país não tem mais "estômago" para confronto. ${ }^{35}$

\section{Os Neoconservadores e o Balanço dos 100 dias de Governo Trump}

Passado o momento de um certo otimismo com as ações do governo americano com a Síria e Coreia do Norte, as reações neoconservadoras voltaram para o espectro de desconfiança e crítica ao presidente. Quando a administração Trump completou 100 dias, vários autores escreveram balanços críticos ao presente.

Kristol aproveitou a ocasião para fazer um balanço da administração, argumentando que seria necessário entender o presidente dentro de uma perspectiva histórica mais ampla, ou seja, ainda que não seja uma época para se ter orgulho da liderança do país, o que se passa seria apenas um momento. Para Kristol, o país encontra-se num período de transições: social, econômica e cultural. Não à toa, o espectro político reage com a encarnação de um líder que de alguma forma articule todas essas mudanças.

Para o autor, a polarização política presente nos Estados Unidos advém deste momento de transições e, portanto, este seria um período crucial para o futuro dos Estados Unidos. Kristol defende que mais do que apenas resistir à ameaça que é Trump, a sociedade americana deveria se concentrar em moldar um futuro positivo com a ideia de que o porvir não depende das debilidades do presidente atual. Para tal, acredita que os nortes a guiarem essa construção 
devem ser a consciência de uma nova ética de responsabilidade, uma nova visão de grandiosidade nacional e, por fim, novas políticas de liberdade. Como bom neoconservador, coloca mais uma vez a democracia liberal como ponto fundamental a guiar este novo momento necessário para o fortalecimento da América. ${ }^{36}$

Já Krauthammer volta ao ataque, mas com certo alívio. Chama Trump de "charlatão", "barulhento" e "sensacionalista". O autor afirma que a Casa Branca representa um cenário de caos, insanidade e incoerência, porém, como Kristol, acredita que exista solução. Apesar da grande apreensão que paira os ares da política americana, o autor admite que poderia ser pior, visto que a ordem internacional continua intacta, a república resiste e nenhum "inimigo do povo" foi preso ainda. Mas fica a questão então: o que fazer? De acordo com o autor, ignorar a figura que está lá presente e torcer para que a burocracia do governo federal possa lidar com os desafios vindouros.

Lowry também voltou suas baterias contra Trump, questionando o comportamento do presidente acerca do suposto envolvimento da Rússia nas eleições americanas e mostrando-se preocupado com a ameaça a credibilidade da Casa Branca no cenário internacional que a figura de Trump traz. ${ }^{37}$ Boot, por sua vez, segue na ofensiva, mas assim como os outros neoconservadores, reconhece que "poderia ser pior".

Em artigos para Foreign Policy, Boot elencou suas principais críticas ao governo do Republicano, observando com pesar que, embora um presidente americano nunca tenha tido uma taxa de reprovação tão elevada, a porcentagem de aprovação do mesmo entre os republicanos ainda era de $84 \%$. Boot lamentou que as pessoas estariam se acostumando com as "barbaridades" ditas pelo presidente e, consequentemente, estariam começando a "aceitar o inaceitável". Todavia, o autor reconhece que a constituição continuaria inabalada e Trump não teria concretizado a maior parte de suas principais promessas de campanha. Porém, não afirma que isso signifique que o presidente tenha tomado rumos moderados, mas confirma apenas que, dos 100 primeiros dias de presidência, o único ponto positivo até então é que Trump não teria transformado em ações aqueles discursos de um candidato incendiário e hiperbólico. ${ }^{38}$

Boot faz uma lista de críticas a Trump: repugna o apoio dado por Trump à então candidata francesa Marie Le Pen, acusando a mesma de ser racista, antissemita, antiamericana e pró-Putin; também salienta a aprovação dada pelo presidente ao egípcio Abdel Fattah al-Sisi, acusado de tortura; destaca as constantes críticas de Trump a importantes aliados de longa data, como México, Canadá e Austrália; recrimina o republicano de usar cargos e poder da Casa Branca para favorecer amigos e parentes; e, por fim, ainda denuncia o presidente de fazer comentários importunos acerca do atentado de 11 de setembro de $2001 .^{39}$ 


\section{Considerações Finais}

"Trump é muito estúpido para ser presidente", afirmou certa vez Max Boot. ${ }^{40}$ Esta frase do neoconservador mais crítico à Trump resume bem a opinião do grupo frente ao presidente norte-americano. Por mais que se observe níveis diferentes de ataque ao presidente alternados com momentos de apoio, particularmente no caso do bombardeio à Síria, o tom prevalecente é de crítica variando entre o ferrenho e o moderado.

Desde as primeiras manifestações de expoentes neoconservadores contra a eleição do então candidato Donald Trump, até as contínuas críticas à sua administração e à sua pessoa, os neoconservadores sempre se colocaram em desfavor ao atual presidente, seja durante a campanha, seja após sua posse. De fato, observou-se que alguns expoentes do pensamento neoconservador, mais notadamente Robert Kagan, chegaram mesmo a apoiar a adversária de Trump nas eleições: a candidata Democrata Hillary Clinton. Aqui cabe um questionamento importante. Conforme afirmado acima, um momento histórico central para a aproximação dos neoconservadores com o Partido Republicano se deu quando os Democratas nomearam George McGovern, considerado excessivamente pacifista e leniente com o regime comunista, como candidato do partido para as eleições de 1972. Esse foi um fator central para a debandada de uma ala insatisfeita com os rumos do pensamento liberal norte-americano que acabou por recuperar temas conservadores a partir de uma perspectiva distinta dos conservadores tradicionais, tendo então recebido a denominação de "neoconservadores". Tendo em vista o que foi apresentado nesse artigo, a pergunta que se coloca atualmente é: teria a eleição de Donald Trump provocado um movimento generalizado de retorno de indivíduos atualmente identificados como neoconservadores para o campo Democrata? Duas diferenças parecem apontar para uma resposta negativa a essa questão.

A primeira diferença em relação a 1972 é o fato de que, ao contrário de McGovern, que foi fragorosamente derrotado nas eleições gerais, perdendo para Nixon em todos os Estados com a exceção de Massachusetts e o Distrito de Columbia, Trump surpreendeu a todos os analistas e derrotou Hillary Clinton, tornando-se o $45^{\circ}$ presidente dos Estados Unidos. Da mesma forma, os Republicanos acabaram sendo bem-sucedidos também nas eleições legislativas, obtendo maioria tanto na Câmara dos Representantes como no Senado. A vitória de Trump teve o efeito de abafar parte do impacto das críticas neoconservadoras ao colocar os Republicanos de volta no governo federal. Como em Washington nada fala mais alto que o poder, o triunfo do candidato Republicano desencorajou qualquer movimento de debandada que pudesse estar nascendo.

Uma segunda diferença tem a ver com o contexto dos anos 70 versus o cenário político de 2016. Mesmo com diferentes nuances, a Guerra Fria ainda provia algum grau de consenso na política externa dos dois principais 
partidos, ao menos entre as elites. Com o final do conflito bipolar, esse consenso desapareceu, e desde a segunda metade dos anos 2000 um crescente grau de polarização política tem complicado ainda mais o cenário. Em que pese as diferenças entre Democratas e Republicanos nos anos 70, bem como os intensos debates que se fortaleciam naquele momento, com direitos civis, Guerra do Vietnã, etc, havia ainda um centro político que em linhas gerais estruturava tanto os partidos como a sociedade. Figuras vistas como distantes desse centro, como era o caso do próprio McGovern, eram rejeitadas pela maior parte da sociedade. Atualmente, com ambos os partidos se afastando um do outro, o que tem permitido a normalização de figuras outrora consideradas radicais, e com o gradual desparecimento de pontos de congruência entre Democratas e Republicanos, fica difícil imaginar um movimento do tipo verificado nos anos 70 .

Portanto, dadas essas diferenças, é bastante improvável um cenário em que indivíduos identificados com o neoconservadorismo abandonem em massa o apoio ao Partido Republicano para se associarem aos Democratas. A despeito das críticas, por vezes bastante pesadas, apresentadas nesse artigo, a saída mais provável para os neoconservadores nos próximos anos será passar a tempestade trumpiana passar para poderem tentar voltar a ter uma maior relevância nas alas Republicanas, ou aguardar alguma outra oportunidade. É preciso lembrar que até o dia 11 de setembro de 2001, os neoconservadores não tinham tanto espaço dentro da administração Bush, que até aquele momento praticava uma política externa com alguns contornos similares a praticada pelo presidente atual. Nada impede que algum evento semelhante venha a alterar a correlação de forças na administração Trump no futuro.

\section{Notas}

1 Professor do curso de Relações Internacionais da PUC-SP e do Programa de Pós-Graduação em Relações Internacionais San Tiago Dantas (PUC-SP/UNESP/UNICAMP), coordenador do Núcleo de Estudos sobre a Política Externa dos Estados Unidos (NEPEU). E-mail: gpteixeira@gmail.com

2 Graduando em Relações Internacionais pela PUC-SP, pesquisador do Núcleo de Estudos sobre a Política Externa dos Estados Unidos (NEPEU). E-mail: jer.calandrelli@gmail.com

3 PODHORETZ, Norman. Neoconservatism: A Eulogy. Commentary, 01 de março de 1996. $<$ https://www.commentarymagazine.com/articles/neoconservatism-a-eulogy/ $>$. Data de acesso: $24 / 05 / 2017$.

4 PODHORETZ, Norman. World War IV: The Long Struggle Against Islamofascism. 2. Ed. Vintage, Estados Unidos, 2008.

5 TEIXEIRA, Carlos Gustavo Poggio. O Pensamento Neoconservador em Política Externa nos Estados Unidos. São Paulo: Editora UNESP, 2010.

6 Idem, p. 52. 
7 Idem, p. 54.

8 Idem, p. 55.

9 STEPHENS, Bret. America in Retreat: The New Isolationism and the Coming Global Disorder. Sentinel, Estados Unidos. 1ª edição. 2014.

10 VAÏSSE, Justin. Neoconservatism, the Biography of a Movement. 1. Ed. Londres: The Belknap Press of Harvard University Press, 2010.

11 TEIXEIRA, Carlos Gustavo Poggio. O Pensamento Neoconservador em Politica Externa nos Estados Unidos. São Paulo: Editora UNESP, 2010, p. 60.

12 Idem, p. 61.

13 VAÏSSE, Justin..op. cit., p. 235.

14 TEIXEIRA, Carlos Gustavo Poggio, op. cit. pp. 64-65.

15 Idem, pp 65-66.

16 VAÏSSE, Justin..op. cit., pp. 223-224.

17 COOPER, Danny. Neoconservatism and American Foreign Policy, a critical analysis. 1a edição. Nova Iorque: Rutledge, 2012. 208 páginas. Citação p. 14.

18 VAÏSSE, Justin..op. cit., p. 235.

19 HUDSON, John. Exclusive: Prominent GOP neoconservative to fundraise for Hillary Clinton. Foreign Policy, 23 de junho de 2016. <http://foreignpolicy.com/2016/06/23/ exclusive-prominent-gop-neoconservative-to-fundraise-for-hillary-clinton/>. Data de acesso: 10/10/2016.

20 KHALEK, Rania. Robert Kagan and other neocons are backing Hillary Clinton, The Intercept, 25 de julho de 2016. <https://theintercept.com/2016/07/25/robert-kagan-andother-neocons-back-hillary-clinton/>. Data de acesso: 10/10/2016.

21 Idem.

22 Idem.

23 Idem.

24 STEIN, Sam. For The Never Trump Movement, An Existential Question: What Now? Huffpost, 20 de setembro de 2016. <http://www.huffpostbrasil.com/entry/never-trump-2016election_us_57e1804be4b0071a6e09e682>. Data de acesso: 27/06/2017

25 KRISTOL, William. \#NeverTrump: A Final Word. The Weekly Standard, 07 de novembro de 2016. $<$ http://www.weeklystandard.com/nevertrump-a-final-word/article/2005275 $>$. Data de acesso: 27/06/2017.

26 KAGAN, Robert. This is how fascism comes to America. Brookings Institution, 22 de maio de 2016. $<$ https://www.brookings.edu/blog/order-from-chaos/2016/05/22/this-is-howfascism-comes-to-america/ $>$. Data de acesso: 10/04/2017.

27 KRISTOL, William. op. cit.

28 BOOT, Max. Let's count the ways Donald Trump has gone where no president has ever gone before. Los Angeles Times, 04 de abril de 2017. <http://www.latimes.com/ opinion/op-ed/la-oe-boot-trumps-broken-norms-20170404-story.html>. Data de acesso: $19 / 04 / 2017$. 
29 KRAUTHAMMER, Charles. My vote, explained. The Washington Post, 20 de outubro de 2017. < https://www.washingtonpost.com/opinions/my-vote-explained/2016/10/20/ b61442a4-96f2-11e6-bc79-af1cd3d2984b story.html?utm term $=.64 f 70 c 0070 d 6>$. Data de acesso: $27 / 06 / 2017$

30 KRAUTHAMMER, Charles. Krauthammer: Trump told our adversaries 'America is back'. Insider Fox News, 07 de abril de 2017. <http://insider.foxnews.com/2017/04/07/ krauthammer-syria-airstrikes-president-trump-message-assad-russia-iran $>$. Data de acesso: 21/04/2017.

31 KRAUTHAMMER, Charles. Trump's great reversal - for now: Steve Bannon and 'America First' are officially in eclipse. NY Daily News, 13 de abril de 2017. < http:// www.nydailynews.com/opinion/trump-great-reversal-article-1.3053438>. Data de acesso: 21/04/2017.

32 LOWRY, Rich. No, Trump Hasn't Become a Neocon. National Review, 18 de abril de 2017. <http://www.nationalreview.com/article/446821/donald-trump-syria-not-a-neocon>. Data de acesso: 21/04/2017.

33 BOOT, Max. Trump must define America's new mission in Syria. Commentary, 07 de abril de 2017. <https://www.commentarymagazine.com/foreign-policy/middle-east/syria/donaldtrump-syria-mission/>. Data de acesso: 19/04/2017.

34 BOOT, Max. Is Trump's Axis of Adults Beating Down the Cabal of Crazies? Foreign Policy, 18 de abril de 2017. <http://foreignpolicy.com/2017/04/18/is-trumps-axis-of-adultsbeating-down-the-cabal-of-crazies/>. Data de acesso: 19/04/2017.

35 KAGAN, Robert. It'll take more than a missile strike to clean up Obama's mess in Syria. The Washington Post, 7 de abril de 2017. <https:/www.washingtonpost.com/opinions/itll-takemore-than-a-m...-1bb9-11e7-bcc2-7d1a0973e7b2 story.html?utm term $=.9535497 \mathrm{fle} 13>$. Data de acesso: 10/04/2017.

36 KRISTOL, William. After Trump. The Weekly Standard, 15 de maio de 2017. <http:// www.weeklystandard.com/after-trump/article/2007918>. Data de acesso: 15/05/2017.

37 LOWRY, Rich. Trump is His Own Worst Enemry. National Review, 12 de maio de 2017. $<$ http://www.nationalreview.com/article/447565/donald-trump-james-comey-trump-hisown-worst-enemy>. Data de acesso: 15/05/2017.

38 BOOT, Max. If Trump Would Only Stop Tweeting, He Might Actually Be a Good President. Foreign Policy, 01 de maio de 2017. < https://foreignpolicy.com/2017/05/01/if-trump-wouldstop-tweeting-he-might-actually-be-a-good-president-white-house-twitter/>. Data de acesso: $15 / 05 / 2017$

39 BOOT, Max. America Is Getting Used to Trump's Insanity. Foreign Policy, 25 de abril de 2017. <https://foreignpolicy.com/2017/04/25/america-is-getting-used-to-trumps-insanity/>. Data de acesso: 15/05/2017.

40 BOOT, Max. Donald Trump Is Proving Too Stupid to Be President. Foreign Policy, 16 de julho de 2017. <https://foreignpolicy.com/2017/06/16/donald-trump-is-proving-too-stupidto-be-president/>. Data de acesso: 27/06/2017

Recebido em 17/05/2017

Aprovado em 22/09/2017 